Brain, Behavior and Evolution
Brain Behav Evol 2014;83:247-265

DOI: $10.1159 / 000360932$
Received: October 10, 2013

Returned for revision: November 6, 2013 Accepted after revision: February 26, 2014

Published online: June 5, 2014

\title{
On the Origin of Grasshopper Oviposition Behavior: Structural Homology in Pregenital and Genital Motor Systems
}

\author{
Karen J. Thompson Alaine D. Jones Sandra A. Miller \\ Department of Biology, Agnes Scott College, Decatur, Ga., USA
}

\section{Key Words}

Grasshopper · Oviposition · Abdominal motor system

\begin{abstract}
In female grasshoppers, oviposition is a highly specialized behavior involving a rhythm-generating neural circuit, the oviposition central pattern generator, unusual abdominal appendages, and dedicated muscles. This study of Schistocerca americana (Drury) grasshoppers was undertaken to determine whether the simpler pregenital abdominal segments, which do not contain ovipositor appendages, share common features with the genital segment, suggesting a roadmap for the genesis of oviposition behavior. Our study revealed that although 5 of the standard pregenital body wall muscles were missing in the female genital segment, homologous lateral nerves were, indeed, present and served 4 ovipositor muscles. Retrograde labeling of the corresponding pregenital nerve branches in male and female grasshoppers revealed motor neurons, dorsal unpaired median neurons, and common inhibitor neurons which appear to be structural homologues of those filled from ovipositor muscles. Some pregenital motor neurons displayed pronounced contralateral neurites; in contrast, some ovipositor motor neurons were exclusively ipsilateral. Strong evidence of structural homology was also obtained for pregenital and
\end{abstract}

ovipositor skeletal muscles supplied by the identified neurons and of the pregenital and ovipositor skeletons. For example, transient embryonic segmental appendages were maintained in the female genital segments, giving rise to ovipositor valves, but were lost in pregenital abdominal segments. Significant proportional differences in sternal apodemes and plates were observed, which partially obscure the similarities between the pregenital and genital skeletons. Other changes in reorganization included genital muscles that displayed adult hypertrophy, 1 genital muscle that appeared to represent 2 fused pregenital muscles, and the insertion points of 2 ovipositor muscles that appeared to have been relocated. Together, the comparisons support the idea that the oviposition behavior of genital segments is built upon a homologous, segmentally iterated motor infrastructure located in the pregenital abdomen of male and female grasshoppers.

๑ 2014 S. Karger AG, Basel

\section{Introduction}

As a question in neurobiology, the capacity of the nervous system to generate diverse innate behavior has enjoyed a long tradition of fruitful research [Arbas et al., 1991; Katz and Harris-Warrick, 1999; Katz, 2010; Can-

\section{KARGER}

E-Mail karger@karger.com

www.karger.com/bbe
(C) 2014 S. Karger AG, Basel

0006-8977/14/0834-0247\$39.50/0
Karen J. Thompson

Department of Biology, Agnes Scott College

141 E College Ave

Decatur, GA 30030 (USA)

E-Mail kthompson@agnesscott.edu 
gliano et al., 2012]. Oviposition of grasshoppers and locusts, for example, is specialized to such an extent that it is hard to imagine how it evolved or even how it develops in every female. The behavior in female grasshoppers is driven by a central pattern generator (CPG) located in the terminal abdominal ganglion [Thompson, 1986a]. This CPG drives rhythmic movements of distinctive appendages on 2 terminal segments of the abdomen. In light of what is known about the development of the grasshopper's nervous system, with its pronounced absence of segmental or sexual differences in neuroblast arrays [Goodman and Bate, 1981; Thomas et al., 1984], a compelling problem is to identify specific sexual and segmental modifications that have led to the emergence of oviposition behavior.

Recent investigations in arthropods have indicated that the evolution of regionally diverse behavior in segments along the longitudinal axis of the animal may involve a coordinated modification of segmental modules of skeleton, muscle, and neurons under the influence of key developmental events controlled by Hox and other segmental identity genes [Jarvis et al., 2012]. The sexually dimorphic oviposition behavior is remarkable in its complexity and in the number of associated specializations. While digging during oviposition, female grasshoppers stand on the ground as their abdomen tip burrows beneath them. The digging movements are produced by the heavily muscled ovipositor valves located on abdominal segments 8 and 9 (A8 and A9). The action of these movable appendages stretches the abdomen after them as the ovipositor digs (up to $10 \mathrm{~cm}$ in Schistocerca americana) and tamps the soil into the sides of the chamber. The motor program can be experimentally activated at any time by severing the descending connections to that ganglion, presumably by a mechanism of release from descending inhibition [Thompson, 1986b]. Also noteworthy is that embryonic females (dissected from eggs) can generate an oviposition motor program that can be recorded from their developing ovipositor muscles [Thompson and Roosevelt, 1998]. Ovipositor appendages are not present in males, nor are they present in the pregenital abdominal segments of either sex. Numerous specializations, in addition to the CPG, are associated with oviposition digging: stress softening of the cuticle between segments [Vincent, 1976], fragmentation of the z-lines of intersegmental muscles [Jorgensen and Rice, 1983] to enable the 6-fold extensions that they endure during egg-laying behavior, specialized alterations of adult muscles [Rose et al., 2001; Rose, 2004], and distinctive sensory systems [Kalogianni, 1996; Tousson and Hustert, 2000; Wani- scheck and Rose, 2005; Newland and Yates, 2008]. Additional neural circuits that control and coordinate oviduct and spermathecal contractions are also present [Lange et al., 1984; Ficcaponte and Lange, 1996; Ayali and Lange, 2010; Da Silva and Lange, 2011].

Our previous work on the terminal abdominal ganglion tested 2 hypotheses for gender differences in behavior. The first hypothesis was that males were deficient, meaning that the male would be missing the ovipositionrelated circuitry. The second was that males would possess oviposition-like structural elements, but they would be functionally respecified for different behavior. Previous research on these ideas in other systems suggested that either or both strategies were possible [Arbas, 1983; McKenna et al., 1991; Truman and Ball, 1998; Whiting et al., 2003]. Strong similarities between male and female motor neurons, but differences in dorsal unpaired median (DUM) neurons [Thompson et al., 1999], were found. In grasshoppers, DUM neurons occur in 2 classes, each with dorsal median cell bodies, and bilateral axons. One type, the efferent neuromodulatory DUM neurons, sends axons to targets in the periphery, including multiple skeletal muscles. The second type, DUM interneurons, are local or intersegmental (GABAergic), and they appear to be involved in sensory processing [Thompson and Siegler, 1991]. For example, while we find the same number of efferent DUM neurons in the A8 segments of males and females, some male DUM neurons project to male genitalia (in A9) through the sexually dimorphic genital nerves. Males do have a smaller number of DUM interneurons in segment A8. However, oviposition-like bursting motor activity could be induced in males [Thompson and Roosevelt, 1998; Fuchs et al., 2006], suggesting that the differences in DUM neurons do not account for the differences in behavioral capacity.

In the present study, we have taken advantage of another aspect of the grasshopper's modular anatomy; that is, we compare a genital segment of females (A8) with the plain pregenital abdominal segments of both males and females. The extent of similarities or differences in the motor system (exoskeleton, muscle, and nerve) will lend insight into the relative levels of morphological diversification underlying the functional specialization for the oviposition digging behavior found in females. The grasshopper's abdomen comprises 11 segments (abdominal segments A1 to A11). The first 7 segments in females (A1 to A7), but the first 8 segments in males (A1 to A8), are considered pregenital. In females, segments A8 and A9 are genital, as each supports a pair of ovipositor valves, but in males only the A9 segment is genital. 
Table 1. Organization of the segmental muscles of a grasshopper's abdomen

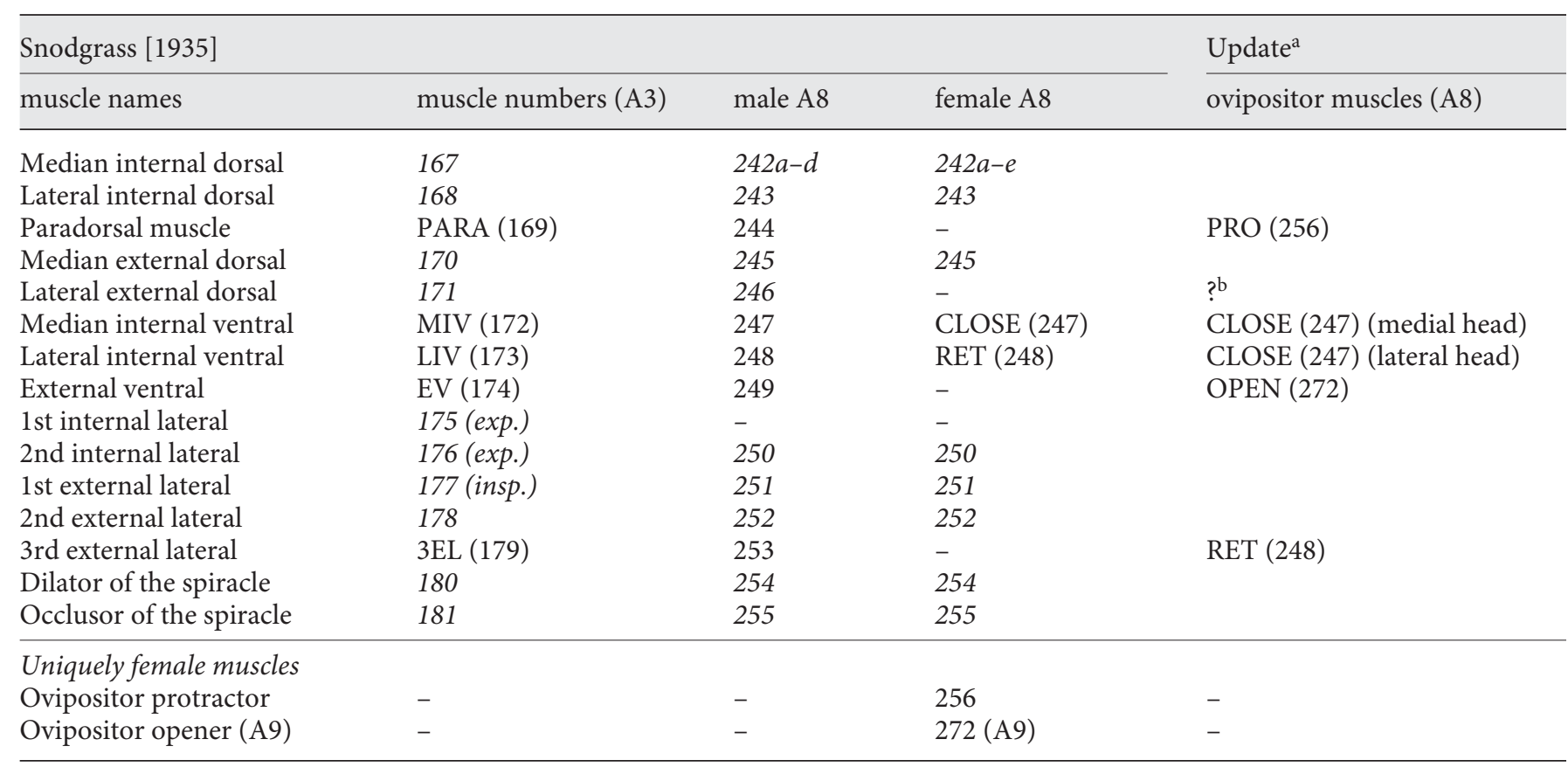

Muscle names and numbers are provided for the third abdominal segment (A3) [Snodgrass, 1935] and for the eighth abdominal segments (A8) of males and females [Snodgrass, 1935; Thompson, 1986a]. Male muscles in A8 correspond to the muscles of a typical pregenital abdominal segment such as A3 minus the first internal lateral muscle, which is missing in both males and females. Italics indicate muscles that are not suggested to comprise oviposition homologues. - = Missing muscles; exp. = expiratory; insp. = inspiratory. a Notes indicate the present view. The numbers of Snodgrass [1935] are not changed, but there are not considered to be any uniquely female muscles in segment A8.

${ }^{\mathrm{b}}$ The issue of this missing muscle remains unresolved. It could possibly correspond to muscle $242 \mathrm{e}$, an additional subcomponent of the dorsal longitudinal muscles that is not present in males; note that males only have $242 \mathrm{a}-\mathrm{d}$.
A standard reiterated set of 15 paired body wall muscles is found in the pregenital abdominal segments of both sexes, as described long ago by Snodgrass [1935]. Segmental repetition and homology are widespread within insects and across insect species [Breidbach and Kutsch, 1990]. The A8 segment, however, is missing one of the usual 15 paired muscles in both males and females. The missing muscle is a ventilatory muscle, i.e. the first internal lateral, 1 of 2 pairs of expiratory muscles (see table 1). A small oblique muscle found in the tergal fold, the lateral external dorsal muscle is also not found in females and, depending upon the species, may be missing in males; compare Seabrooke [1968] and Snodgrass [1935]. In addition, 5 more pregenital muscles are not found in the female segment A8 [Snodgrass, 1935]. Each of these muscles is clearly present in the corresponding male segment. The missing muscles in females are the external ventral (EV), median internal ventral (MIV), lateral in- ternal ventral (LIV), third external lateral (3EL), and paradorsal (PARA) (see table 1). Although females are missing these 5 muscles in segment A8, 4 ovipositor muscles are present: ovipositor openers (OPEN), closers (CLOSE), retractors (RET), and protractors (PRO) [Snodgrass, 1935; Thompson, 1986a].

An earlier publication by Seabrooke [1968] described the innervation of abdominal muscles in locusts, S. gregaria. Suggestively, the innervation pattern of ovipositor muscles appeared to match the innervation pattern of pregenital body wall muscles that were thought to be missing in the eighth abdominal segment of females. In order to characterize pregenital neurons for morphological comparison with previously identified ovipositor neurons and thereby gather more specific information about possible structural homology, efferent neurons with axons in the nerve branches were labeled retrogradely from the periphery and analyzed in pregenital segments of 
both male and female grasshoppers. Additionally, aspects of embryonic pregenital and genital abdominal appendages were examined and the development of the ovipositor valves was characterized. Pregenital and genital musculoskeletal systems were further compared and contrasted. Our results point to both segmental uniformity and segmental divergence of neuromuscular systems of pregenital and genital segments.

\section{Materials and Methods}

S. americana (Drury) males and females were obtained from our laboratory colony. More than 218 adult animals were used for backfill studies, additional embryos and larvae were used for scanning electron microscopy, and many adults were also dissected to analyze nerve branching patterns and muscle anatomy. Anatomical nomenclature was based on Snodgrass [1935], Albrecht [1953], Seabrooke [1968], and Thompson [1986a]. For the present study, we focused on abdominal segments A4 to A7 in males and A4 to A6 in females. There are two reasons for this strategy. Neuromeres A 1 to $A 3$ are fused to the metathoracic ganglion and thus not free in the abdomen for ready comparison. In females, ganglion A7 supplies the oviduct and contains the cell bodies of some ovipositor muscles, so we do not consider the male A8 and the female A7 segments to be fully pregenital. In the present study, we utilize the segment A8 of females as the behaviorally specialized segment; the segment A9 of females is also involved in oviposition [Snodgrass, 1935; Thompson, 1986a; Thompson et al., 1999], but it is not the focus here. To identify efferent neurons, nerves or nerve branches were filled by retrograde transport of cobalt chloride ( $0.1 \%$ weight/ volume) followed by precipitation with hydrogen sulfide gas and silver intensification as described in more detail elsewhere [Thompson and Roosevelt, 1998]. To backfill the smallest of nerve branches, a piece of muscle was left attached to the end of the nerve. With the muscle bit attached, the nerve branch could be manipulated much more readily. The labeling method was developed to optimize the motor neuron structure. DUM neurons are also labeled but more palely than motor neurons unless the intensification process is extended longer than is desirable for motor neurons. Consequently, in some preparations, the number of DUM neurons may be underestimated. See also the descriptions of Schmitt [1954], Lewis et al. [1973], and Burrows and Bevan [1999]. Whole-mounted ganglia were examined and photographed or drawn with the aid of a camera lucida drawing tube attached to a Zeiss compound microscope (Carl Zeiss Inc., Jena, Germany).

Tissues examined by scanning electron microscopy were prepared by fixing in $0.1 \mathrm{M}$ sodium cacodylate-buffered ( $\mathrm{pH} 7.4$ ) $6.25 \%$ glutaraldehyde and dehydrated to $100 \%$ ethanol. This was followed by critical-point drying. Specimens were coated with Au:palladium and examined with an AMR model 1000A scanning electron microscope (AMRAY Inc., Bedford, Mass., USA). All chemicals were purchased from Sigma-Aldrich (St. Louis, Mo., USA).

\section{Results}

\section{Development of the Ovipositor Valves from}

\section{Appendage Rudiments}

Embryonic grasshoppers display a uniform pattern of paired ventral appendages on each body segment extending from the head to the thorax to the terminal abdomen (fig. 1A). The appendages are present from around 30\% to just after $55 \%$ of embryonic development, with fertilization at $0 \%$ and hatching at $100 \%$ according to the scheme of Bentley et al. [1979]. The serially homologous appendages represent the embryonic rudiments of such diverse adult structures as antennae, mouthparts, legs, cerci, and, in females, the 2 pairs of ovipositor valves [Qadri, 1940; Matsuda, 1976]. In pregenital abdominal segments, the limb buds are reabsorbed during development, but not before they participate in peripheral nerve path finding [Meier et al., 1991]. As shown in figure 1B, nascent ovipositor valves in newly hatched females are visible as paired outgrowths of the posterior margins of segments A8 and A9. Valve contours enlarge and differentiate in a series of steps across the 5 larval stages, and by the third instar the valves have changed from their original anterior/posterior arrangement to the adult ventral/dorsal orientation. This shift is due to growth of the valves combined with a dramatic reduction of the ninth sternal plate between them (compare B ii-v). In the fourth and fifth larval stages the valves continue to enlarge with each molt, such that they extend beyond the abdomen tip at the final molt to adulthood (B vi). The soft valves enlarge further and become densely sclerotic during 2 or 3 more weeks while the animal is growing into sexual maturity. Adult muscles also demonstrate enormous hypertrophy, as do the underlying ovipositor apodemes, during this period of time (fig. 1C). Thus, compared to the unadorned pregenital segments, the genital segments of females are distinguished by the presence of paired appendages that together comprise the moveable ventral (A8) and dorsal (A9) ovipositor valves.

\section{Comparison of Pregenital and Ovipositor Nerve Supplies}

In adults, the pregenital abdomen comprises similar repeating segments. The ventral nerve cord in the abdomen consists of the 4 unfused ganglia of segments A4 to A7 and the fused terminal abdominal ganglion (A8-11, fig. 2C). Our comparative analysis of the morphology of the abdomen has indicated that the musculature of the prototypical pregenital segment (A3) which is followed in the remaining pregenital segments can also be detect- 
Fig. 1. Embryonic, larval, and adult development of the ovipositor. A Scanning electron micrograph of a $38 \%$ stage grasshopper embryo (ventral view) showing paired ventral appendages on every body segment. The ventral and dorsal ovipositor valve rudiments of abdominal segments 8 and 9 are indicated. B Differentiation of the ovipositor through 5 sequential larval stages (i-v) and in a newly molted adult (vi), scanning electron micrographs of abdomen tips (ventral view). The ventral (V, pink) and dorsal (D, blue) ovipositor valves develop as posterior outgrowths of the sternal plates of segments A8 and A9 and then enlarge while the A9 plate (9st) between them shrinks. Further enlargement and extension beyond the abdomen tip occurs during the later larval stages and molt to adulthood. C Dissection of ovipositor OPEN muscles (yellow) of the ventral valves (A8) in a 2-day-old adult (left) and a 6-week-old sexually mature adult (right) (colors refer to the online version only). The OPEN muscles and underlying apodemes enlarge during adult development. Scale bars $=200 \mu \mathrm{m}($ B $)$ and 400 $\mu \mathrm{m}(\mathbf{C})$.
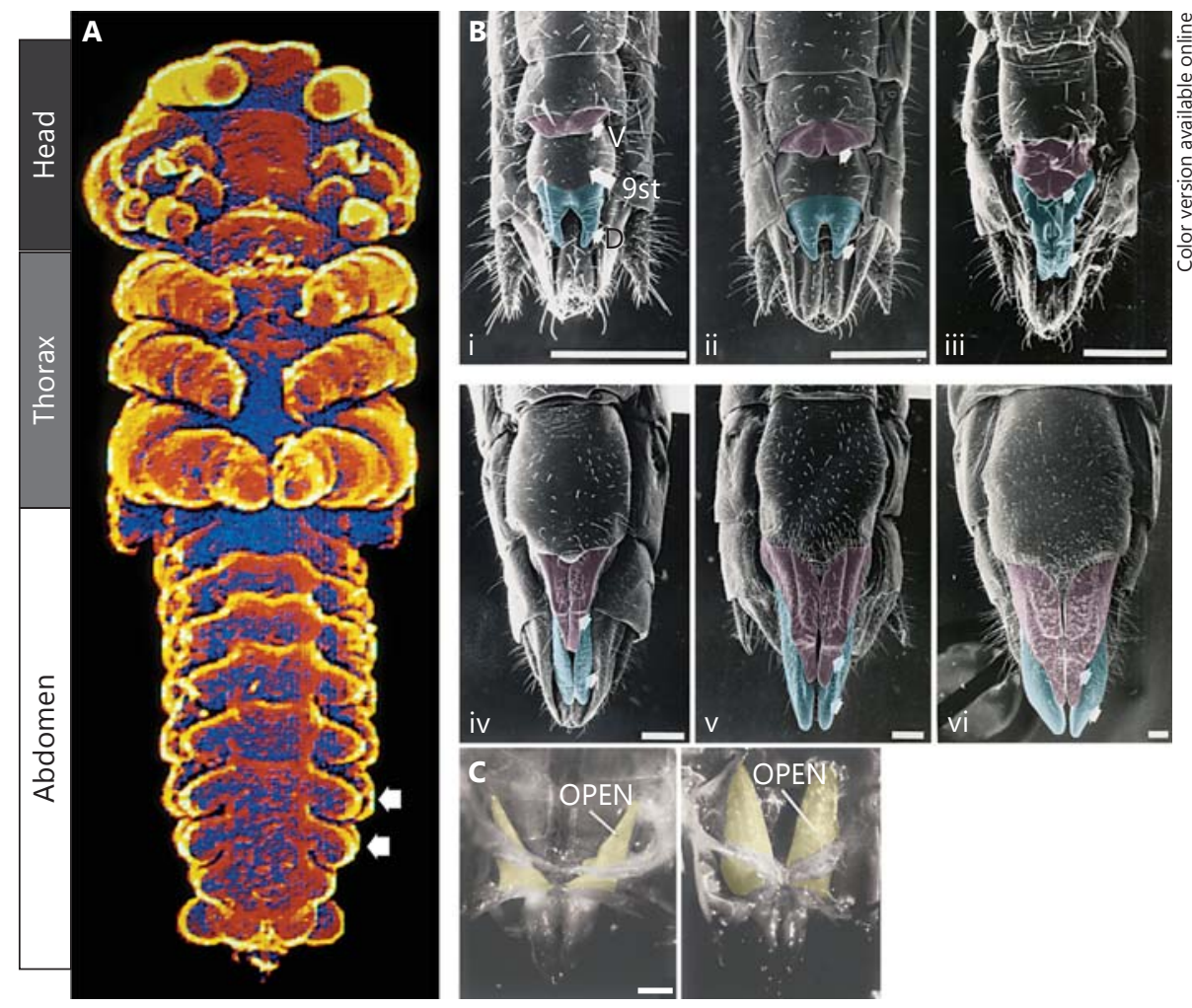

ed in a modified state in the A8 segment of females. By comparing innervation patterns and muscle attachments, a full alignment of structures emerges. The initial morphological analysis by Snodgrass [1935] was that 1 of the 15 standard pregenital body wall muscle pairs was missing in the segment $\mathrm{A} 8$ of males, but this and 5 more muscles were missing in the segment A8 of females (table 1). Snodgrass [1935] observed that the first internal lateral muscle was missing in the A8 of both males and females. He further concluded that, of the remaining muscles, the PARA muscle, the LEV muscle, the EV muscle, the 3EL muscle, and the LED muscle were specifically missing in the female segment A8. Snodgrass [1935] was also under the impression that the ovipositor PRO was a muscle added to A8, and the ventral ovipositor OPEN muscle belonged to A9. Snodgrass [1935] reasoned that the ovipositor CLOSE muscle was a likely serial homologue of the pregenital MIV muscle, and that the ovipositor RET muscle corresponded to the pregenital LIV muscle. As we show below, our results indicate instead that the RET corresponds to the 'missing' 3EL muscle, and also that the lateral head of the CLOSE muscle, not the RET, represents the 'missing' LIV muscle. Further, we suggest that the PRO is not a muscle added to A8 but is instead another homologue, this time of the 'missing' PARA muscle of pregenital segments. In addition, the ovipositor OPEN appears to represent the 'missing' EV muscle of pregenital segments. Thus we suggest, based on evidence provided below, that muscles specifically missing in the female A8 may actually be present, recast as ovipositor muscles.

The patterns of the lateral nerve supply to pregenital and ovipositor muscles are such that each ovipositor muscle is supplied by a lateral nerve branch that corresponds to a branch that supplies pregenital muscles missing in the A8 segment of females (fig. 2A, B). The ovipositor PRO and CLOSE muscles are supplied by nerve 1 ( $\mathrm{Nv} 1$, fig. 2B), while nerve 2 ( $\mathrm{Nv} 2$ ) supplies the ovipositor RET and OPEN muscles (fig. 2B). Note that the ovipositor CLOSE muscle has 2 heads that are supplied by distal bifurcations of the first posterior-going branch of $\mathrm{Nv} 1$. The corresponding 2 distal branches of $\mathrm{Nv} 1$ in pregenital segments separately supply the MIV and LIV muscles (fig. 2A). Nv 1 in A8 continues laterally to supply standard body wall muscles and also the ovipositor PRO muscle (fig. 2B). In pregenital segments, the matching standard body wall muscles receive a similar innervation from Nv 1, and the branch corresponding to the oviposi- 
Fig. 2. Lateral nerves and muscle innervations by pregenital abdominal ganglia and by segment $\mathrm{A} 8$ of the female terminal abdominal ganglion. A Diagrammatic view of the Nv 1 and Nv 2 supply to pregenital body wall muscles. The muscles indicated by colored bubbles (PARA, MIV, LIV, 3EL, and EV) are absent in the female genital segment (B). The innervation of ovipositor muscles (CLOSE and PRO by $\mathrm{Nv} 1$, and RET and OPEN by Nv 2) and the body wall musculature in the female segment A8 of the terminal abdominal ganglion are indicated with colors of bubbles corresponding to the matching nerve branch in pregenital segments (colors refer to the online version only). The numbers used in the pregenital diagram are given for the male A8, which is considered to be pregenital, and A3 muscle numbers are in parentheses. Muscle numbers are after Snodgrass [1935], and see figure 8 a. For identification of all muscles, see table 1. C Diagram of the ventral view of a female grasshopper abdomen with a ventral nerve cord, indicating the pregenital region with the unfused abdominal ganglia A4 to A7, and the terminal abdominal ganglion which is genital (A8 to A11).

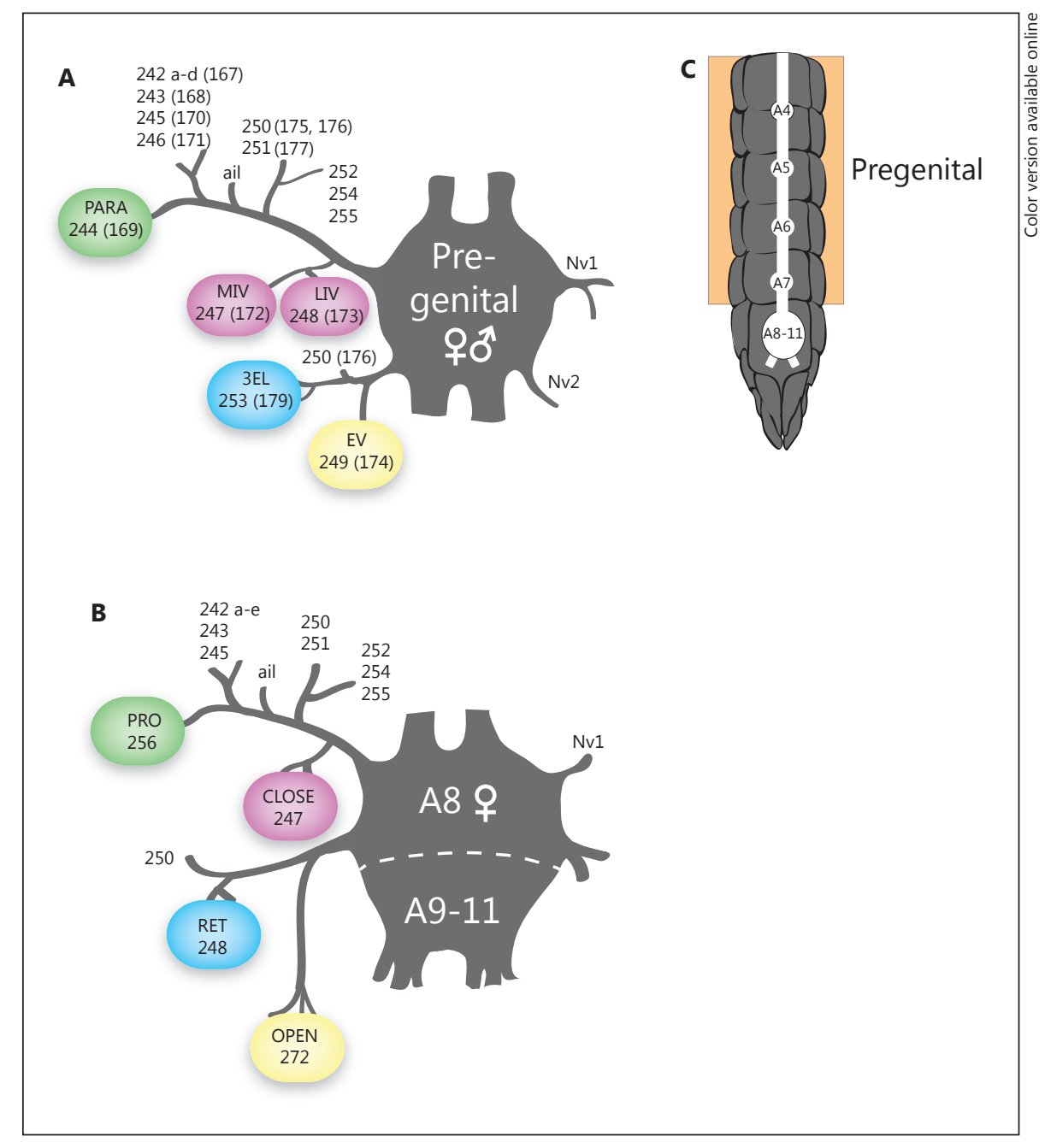

tor PRO branch (fig. 2B) in pregenital segments supplies the PARA muscle (fig. 2A).

The thick first posterior branch of Nv 2 supplies the large ovipositor OPEN muscle in segment A8 (fig. 2B). The corresponding, but much thinner, posterior branch of $\mathrm{Nv} 2$ in pregenital segments supplies the EV muscle (fig. 2A). Finally, a distal lateral branch of Nv 2 supplies the ovipositor RET muscle (fig. 2B) and the 3EL muscles in pregenital segments (fig. 2A) as well as standard body wall musculature that matches between segments. It thus appears that the $4 \mathrm{~A} 8$ ovipositor muscles of females are supplied by nerve branches corresponding to those of the 5 pregenital muscles that appeared to be 'missing' in the female A8 (the MIV and LIV muscles consolidated into the ovipositor CLOSE muscle).

\section{Efferent Neurons of Pregenital and Ovipositor Segments}

To extend the comparison of pregenital and genital segments, efferent pregenital neurons were identified by retrograde labeling through entire lateral nerves and then through the final branches to pregenital muscles missing from segment A8 of females. Some ovipositor muscle and A8 lateral nerve backfills of males and females have previously been described [Thompson, 1986a; Thompson and Roosevelt, 1998].

Based on morphological characteristics, neuron types identified in this study included motor neurons, DUM neurons, and common inhibitor (CI) neurons [Ferber and Pfluger, 1990; Schmah and Wolf, 2003]. Table 2 describes the populations of 3 types of labeled neurons and their locations. Most typically, the variation between preparations was small. Efferent neurons were compa- 
Table 2. Efferent neuron populations labeled in backfill preparations of whole lateral nerves of pregenital ganglia and female terminal abdominal ganglion A8

\begin{tabular}{|c|c|c|c|c|c|}
\hline \multirow[t]{2}{*}{ Nerve and cell body locations } & \multirow[t]{2}{*}{ MNs } & \multirow[t]{2}{*}{ DUM } & \multirow[t]{2}{*}{$\mathrm{CI}$} & \multicolumn{2}{|c|}{ Animals, $\mathrm{n}$} \\
\hline & & & & males & females \\
\hline Pregenital Nv 1 & & & & 24 & 22 \\
\hline Female Ovip Nv 1 & & & & & 22 \\
\hline Pregenital Ant Adj & $20(16-20)$ & 0 & $2(0-2)$ & & \\
\hline Ovip Ant Adj (A7) & $20(13-21)$ & 0 & $2(0-2)$ & & \\
\hline Pregenital Local & $8(6-8)$ & $4(0-5)$ & $1(0-1)$ & & \\
\hline Ovip Local (A8) & $5(4-5)$ & $1(0-1)$ & $1(0-1)$ & & \\
\hline Pregenital Nv 2 & & & & 19 & 17 \\
\hline Female Ovip Nv 2 & & & & & 27 \\
\hline Pregenital Local & $12(9-14)$ & $8(5-14)$ & 0 & & \\
\hline Ovip Local (A8) & $14(12-18)$ & $6(5-6)$ & 0 & & \\
\hline
\end{tabular}

Specific types of neurons identified in backfill studies were counted in 43 male and 39 female pregenital ganglion preparations and in 49 female terminal abdominal ganglion preparations (Ovip). Entire lateral Nv 1 and Nv 2 were filled and the median number of motor neurons (MNs), DUM and CI neurons are indicated. The range of cell counts is indicated in parentheses. Nv 1 backfill preparations labeled neurons in the anterior adjacent ganglion (Ant Adj) as well as the local ganglion (Local). All cell bodies identified in Nv 2 backfills were located in the local ganglion.

rable in nerve backfill preparations of pregenital ganglia from males and females. In pregenital Nv 1 fills (fig. 3A, $\mathrm{B}, \mathrm{D}$ ), the local ganglion contained 2 contralateral groups of motor neurons, with 3 cell bodies each, and an ipsilateral pair of motor neurons. The axons of the ipsilateral neurons travel in a small lateral nerve that leaves the ganglion posterior to the main $\mathrm{Nv} 1$ but joins with $\mathrm{Nv} 1$ at varying distances from the ganglion (fig. $3 \mathrm{~A}, \mathrm{~B}, \mathrm{D}$ ). This branch is exceedingly fragile and thin, thinner still in males, and in 7 preparations where these neurons were not stained $(n=24)$ the lateral nerve branch was also not stained. These 2 neurons appear to provide the only axons carried in the small branch. The local ganglion also contained at least posterior and anterior DUM neurons, with a median of 4 DUM neurons (range $0-5$, see table 2 ). A single ventral medial neuron that had CI morphology and a palely stained multiaxon neuron were also stained (shown clear in the diagrams, fig. 3D, E). The cell bodies filled in the anterior adjacent ganglion included an ipsilateral cluster of 10 motor neurons, a more posterior ipsilateral cluster of 6 motor neurons, a single slightly more medial posterior motor neuron, and 5 midline neurons, the 2 largest of which appeared to be CIs (fig. 3A, B, D), 20 motor neurons, and 2 CIs. Only minor differences were found between this description and the distribution of neurons filled from $\mathrm{Nv} 1$ of the female A8 segment (compare fig. 3C, E, and table 2). Instead of 3 motor neurons, the anterior contralateral group in the local ganglion contained 2 motor neurons in the female segment A8. In addition, the 2 ipsilateral local motor neurons found in pregenital ganglia were not represented in segment A8, and the small lateral nerve joining $\mathrm{Nv} 1$ in pregenital segments also was not present, meaning that Nv 1 backfills of segment A8 labeled 3 fewer motor neurons in the local ganglion. A single DUM neuron was found in A8. The anterior adjacent ganglion (A7) contained efferent neurons similar to those found in the anterior adjacent ganglion from pregenital Nv 1 fills (fig. 3).

Retrograde fills of Nv 2 labeled ipsilateral motor neurons, consisting of a cluster of 5 motor neurons in the pregenital ganglion (fig. 4A, B, D) and 7 or 11 neurons in the female A8 (fig. 4C, E), all with cell bodies near the base of Nv 2. Many of our preparations labeled 7 motor neurons, specifically the OPEN motor neurons (see below), but 4 more motor neurons were labeled in preparations where the branch to the spermatheca was also filled, bringing the total in these preparations to 11 (see table 2). In addition, a more anterior ipsilateral cluster of 7 motor neuron cell bodies was labeled in pregenital and female A8 backfills (fig. 4). The number of DUM neurons was larger and more variable in our preparations of pregenital segments (median 8, range 5-14) than in female A8 prep- 


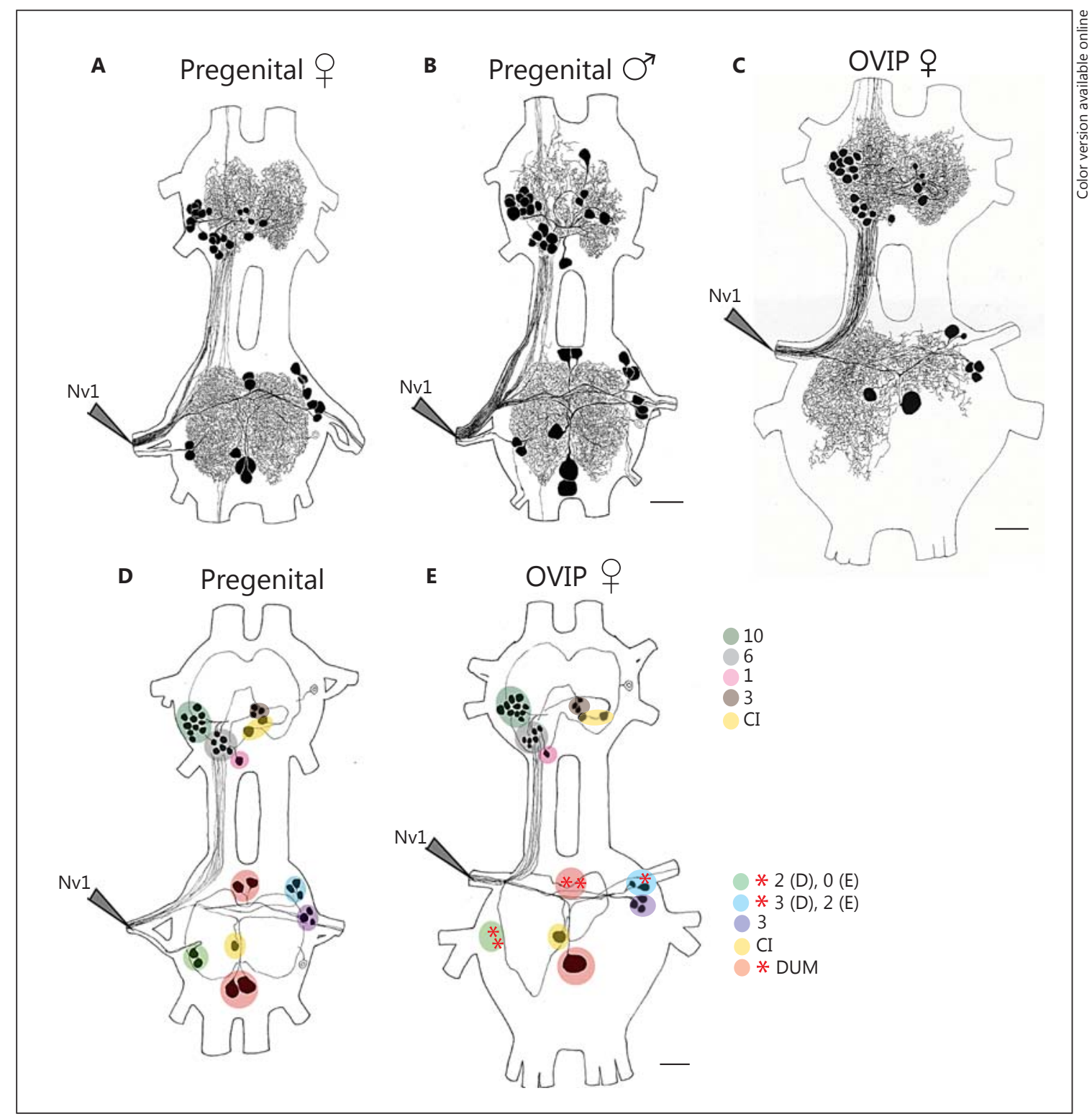

Fig. 3. Efferent neuron populations labeled by backfilling $\mathrm{Nv} 1$ of pregenital ganglia and the female segment $\mathrm{A} 8 \mathrm{Nv} 1$ of the terminal abdominal ganglion. Pregenital female (A) and male (B) ganglia (camera lucida drawings) and summary diagram of the pregenital neuron groups (D). Camera lucida drawing of neurons labeled from Nv 1 of the female A8 (C, OVIP), and summary diagram of the neurons filled in the terminal abdominal ganglion and in A7 (E). Labeled neurons in pregenital preparations included cell bodies in the local ganglion and in the anterior adjacent ganglion, comprised of clusters of motor neurons, CI neurons, and DUM neurons in the local ganglion, as well as additional motor neurons and CI neurons located in the anterior adjacent ganglion. Pregen- ital male and female results were similar. Female A8 Nv 1 fills labeled similar groups of neurons, except that the female terminal abdominal ganglion was missing the ipsilateral cluster of 2 motor neurons and 1 of the contralateral rostral motor neurons in the local ganglion (asterisks in E). Pregenital ganglia also contained more DUM neurons compared to the terminal ganglion which contained one. The key indicates the median cell body numbers for corresponding groups of motor neurons and CI and DUM neurons in $\mathbf{D}$ and $\mathbf{E}$. OVIP refers to the A8 neuromere of the terminal abdominal ganglion which is specialized for oviposition. Scale bar $=100 \mu \mathrm{m}$ (colors refer to the online version only). 


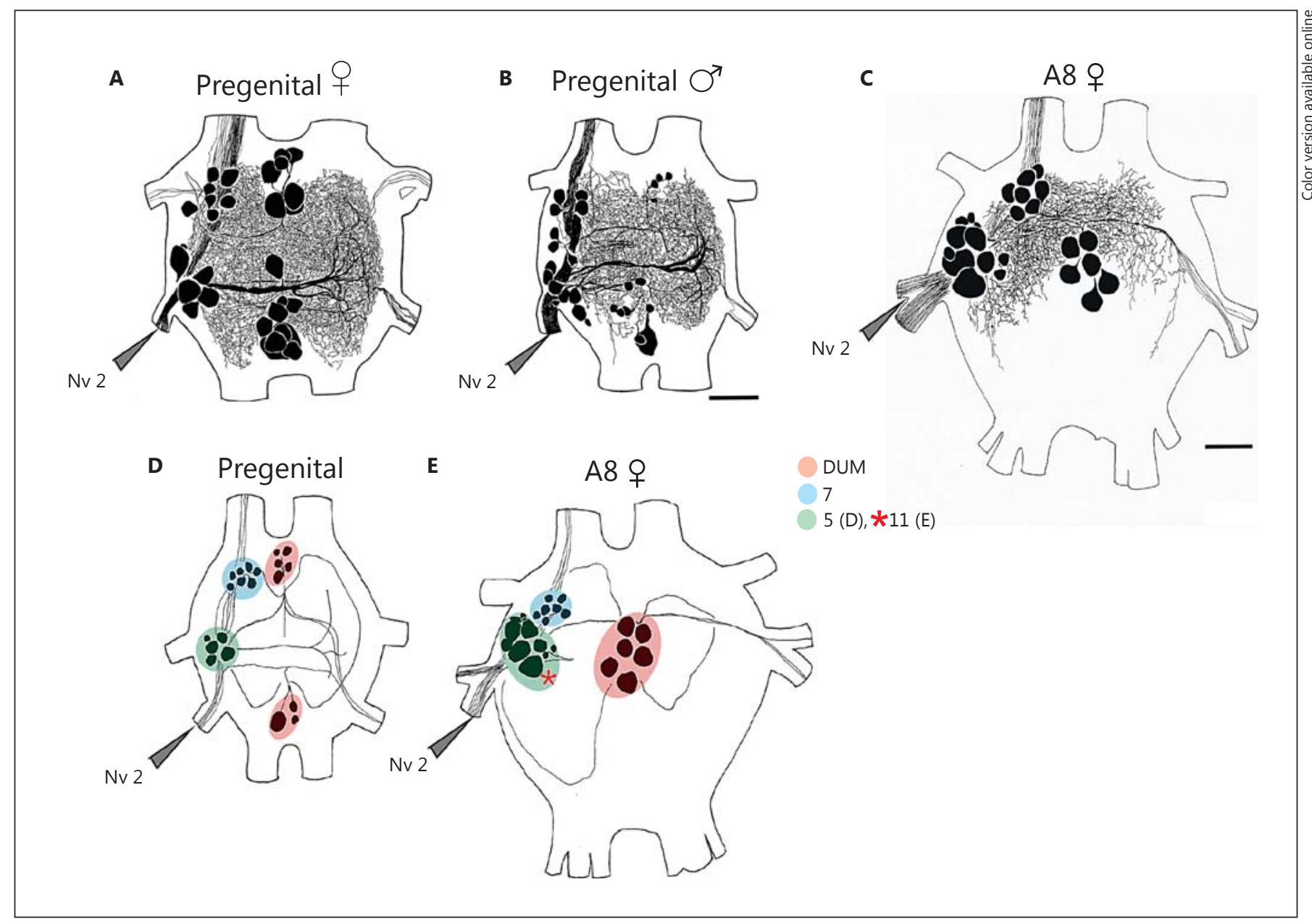

Fig. 4. Efferent neuron populations labeled by backfilling Nv 2 of pregenital ganglia and the female segment $\mathrm{A} 8 \mathrm{Nv} 2$ of the terminal abdominal ganglion. Female (A) and male (B) pregenital abdominal ganglia and female terminal abdominal ganglion (C). Camera lucida drawings (A-C) and summary diagrams (D, E). All cell bodies of motor neurons and DUM neurons were confined to the local ganglion in Nv 2 fills. Pregenital female DUM neurons appeared noticeably larger than male DUM neurons. Two small motor neu- rons in the posterior cluster of large motor neurons in the female segment A8 were not found in pregenital ganglia, and the terminal abdominal ganglion contained 6 DUM neurons while pregenital ganglia contained up to 14 (see table 2), and their cell bodies were smaller in males. The key indicates the median cell body numbers for corresponding clusters of neurons in $\mathbf{D}$ and $\mathbf{E}$. Scale bar $=100$ $\mu \mathrm{m}$ (colors refer to the online version only). arations (median 6, range 5-6). Female pregenital ganglia also contained larger DUM neurons than male ones (compare fig. 4A, B). Pregenital DUM neurons are described more fully by Ferber and Pfluger [1990].

\section{Neurons in Pregenital Segments to Muscles Missing in} the Female Segment A8

Selective backfills of the final nerve branches to the 5 pregenital muscles that were missing in the female A8 segment revealed motor neurons, DUM neurons, and CI neurons. They occurred in a pattern that closely matched the previous findings from the ovipositor (fig. 5, 6; table 3). The results from pregenital ganglia were similar between the sexes, and representative preparations are shown here, rather than showing male and female neurons of every pregenital ganglion. The morphology of ovipositor neurons in segment A8 is shown on the right side of figures 5 and 6 . Other examples are found in Thompson and Roosevelt [1998] and Thompson et al. [1999]. Table 3 documents the number of preparations and the median and range of neurons of each type labeled. 


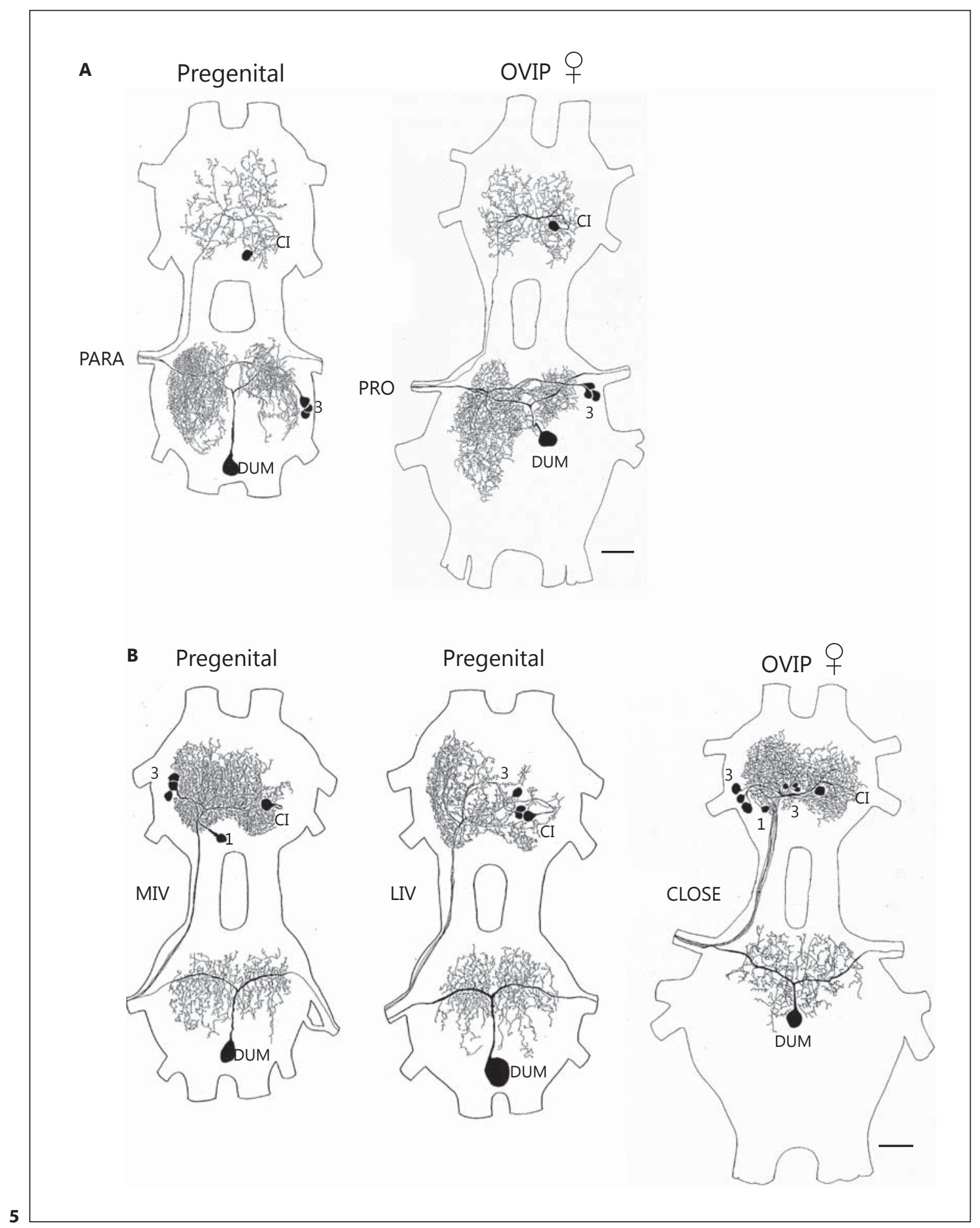

(For legend see next page.) 
Selective backfills of the distal lateral branch of $\mathrm{Nv} 1$ (see fig. 2A) to the pregenital PARA muscle revealed 3 contralateral motor neuron cell bodies in the local ganglion (fig. 5A, left), in a tight cluster just posterior to the location of the 3 dorsal longitudinal motor neuron cell bodies (the anterior cluster in fig. 3D). Fine neurite branches were located predominantly ipsilateral to the nerve and dorsal in the neuropile, on the opposite side of the ganglion from the cell bodies. This morphology closely corresponds to that of the 3 previously identified ovipositor PRO motor neurons with axons in a distal lateral branch of Nv 1 in the female A8 (fig. 5A, right). In addition, a single DUM neuron was filled and, in the anterior adjacent ganglion, a CI type neuron was found; these are features that similarly characterize ovipositor PRO nerve backfills (fig. 5A, right). The similarity of neuron forms is more pronounced when it is remembered that the A8 neuromere occupies only the rostral half or third of the terminal abdominal ganglion.

The first posterior branch of Nv 1 bifurcates shortly before it supplies the MIV and LIV muscles in pregenital segments (see fig. 2A). The medial branch supplies the MIV muscle and the lateral branch supplies the LIV muscle. Backfills from the medial branch label 3 motor neurons in the anterior adjacent ganglion among the ipsilateral cluster of 10 cell bodies (shown in fig. 3D), a single more posterior motor neuron, and a CI neuron (fig. 5B, left). Backfills from the other branch of the $\mathrm{Y}$, to the pregenital LIV muscle (see fig. 2A), label 3 small midline cell bodies and also the same $\mathrm{CI}$ neuron in the anterior adjacent ganglion (fig. 5B, middle). The ovipositor CLOSE

Fig. 5. Efferent neurons labeled from $\mathrm{Nv} 1$ branches to pregenital PARA and MIV, LIV muscles and to ovipositor PRO and CLOSE muscles. Camera lucida drawings of pregenital neurons and ovipositor neurons filled from corresponding lateral nerve branches in segment A8 (right). The numbers of motor neurons are indicated and DUM and CI neurons are labeled. A Pregenital PARA neurons (left, segment A6 Nv 1 female) and ovipositor PRO neurons (right). Three contralateral local motor neurons, 1 local DUM neuron, and a CI neuron in the anterior adjacent ganglion were labeled in both preparations. B Pregenital MIV neurons (left) included 4 motor neurons and a CI neuron in the anterior adjacent ganglion (filled from male A5 Nv 1), as well as 1 DUM neuron in local ganglion. Pregenital LIV neurons (middle) included 3 motor neurons and a CI neuron in the anterior adjacent ganglion (filled from female A6 Nv 1) and the same DUM neuron in the local ganglion. Ovipositor CLOSE neurons (right) comprised 7 motor neurons and a CI neuron in the anterior adjacent ganglion (A7), and 1 local DUM neuron (in A8 of the terminal abdominal ganglion). Scale bar $=100 \mu \mathrm{m}$.

Grasshopper Abdominal Motor Systems muscle is composed of 2 distinct parts; the innervation of the medial part of the CLOSE muscle appears to correspond to the MIV, innervated by 4 similar motor neurons and a CI neuron, while the innervation of the lateral part corresponds to the LIV [Thompson, unpubl. obs.], with its innervation by 3 small midline neurons and a single CI neuron (fig. 5B, right). In addition, a single DUM neuron was labeled by either backfilling from the pregenital MIV/ LIV nerve trunk or from the nerve to the CLOSE muscle. The pregenital MIV/LIV and the ovipositor CLOSE are thus both supplied by a total of 9 neurons with axons in the first branch of the lateral nerve: 7 motor neurons and $1 \mathrm{CI}$ type in the anterior adjacent ganglion, and 1 local DUM neuron. It appears that a single DUM neuron supplies the MIV, LIV, and PARA muscles in pregenital segments [Ferber and Pfluger, 1990], as a single DUM neuron supplies the ovipositor CLOSE and PRO muscles.

Retrograde labeling of the distal lateral branch of Nv 2 to the 3EL muscle (fig. 2B) exposed 2 motor neurons in the ipsilateral anterior region of the local pregenital ganglion (fig. 6A, left). In segment A8, two motor neurons in the corresponding position were filled from the matching nerve branch to the ovipositor RET muscle (fig. 6A, right). Fine branches were predominantly ipsilateral and dorsal, with indications of neurites crossing to the contralateral neuropile. No DUM or CI neuron was found in backfills of the ovipositor RET muscle or the 3EL muscle. The final branch to the 3EL muscle in pregenital segments is exceedingly short, and our attempts to backfill it without filling the entire lateral branch were only successful in 4 out of 7 preparations (table 3 ). We are less confident of this result than the others, but our backfills of the lateral branch of Nv 2 always stained from 2 to 7 anterolateral neurons in the local ganglion, with fine dorsal processes branching ipsilaterally and to some extent contralaterally in the neuropile and no CI or DUM neurons.

The first posterior branch of $\mathrm{Nv} 2$ supplies the EV muscle of pregenital segments (fig. 2B). The large ovipositor OPEN muscle is likewise supplied by the first posterior branch of Nv 2 in segment A8. In pregenital segments, retrograde labeling from the EV muscle revealed 5 motor neurons with ipsilateral cell bodies near the base of the nerve (fig. 6B, left). The 2 largest of these neurons, similarly in both male and female pregenital ganglia, were distinguished by having strikingly thick $(10-12 \mu \mathrm{m})$ contralateral neurites with extensive fine branches curving around the margins of the contralateral neuropile. Backfills of EVs also revealed a single local DUM neuron, but $\mathrm{CI}$ neurons were not found. Five ovipositor OPEN motor neurons had large cell bodies located near the root of $\mathrm{Nv}$ 
Fig. 6. Efferent neurons labeled from Nv 2 branches to pregenital 3EL and EV muscles and to ovipositor RET and OPEN muscles. Cameral lucida drawings (left) of pregenital ganglia, a female A5 ganglion (A), and a male A6 ganglion (B) paired with ovipositor neurons (right, A, B). The numbers of motor neurons are indicated and DUM neurons are identified. A Pregenital 3EL neurons (left) and ovipositor RET neurons (right). In both, 2 motor neurons, but no DUM or CI neurons, were labeled. B Pregenital EV neurons (left) included 5 motor neurons and 1 DUM neuron. Ovipositor OPEN neurons (right) included 7 motor neurons, 2 of which had very small cell bodies, and a single DUM neuron. The camera lucida drawing of EV motor neurons (left) demonstrates thick commissural neurites and dense fine neurites in the contralateral neuropile, features that are not found in female $\mathrm{Nv} 1$ fills in A8 (right). C Prominent contralateral neurites of male A8 EV neurons (left) compared to female OPEN neurons (right). Light micrographs of cobalt backfilled preparations. The cell bodies of the motor neurons in both images are out of focus near the base of $\mathrm{Nv} 2$, which is on the left of the micrographs. The DUM neuron was only weakly stained in the female preparation. Scale bar $=100 \mu \mathrm{m}$.
A

Pregenital

$3 E L$

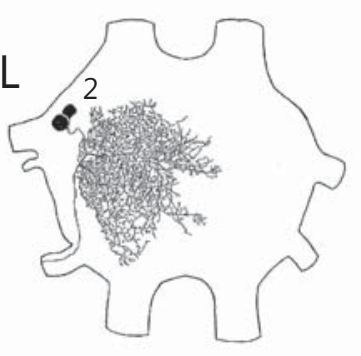

RET

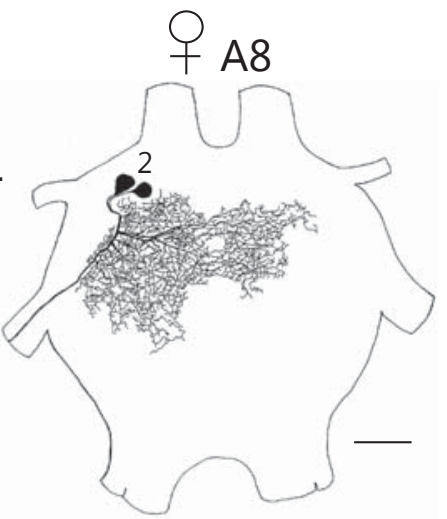

B
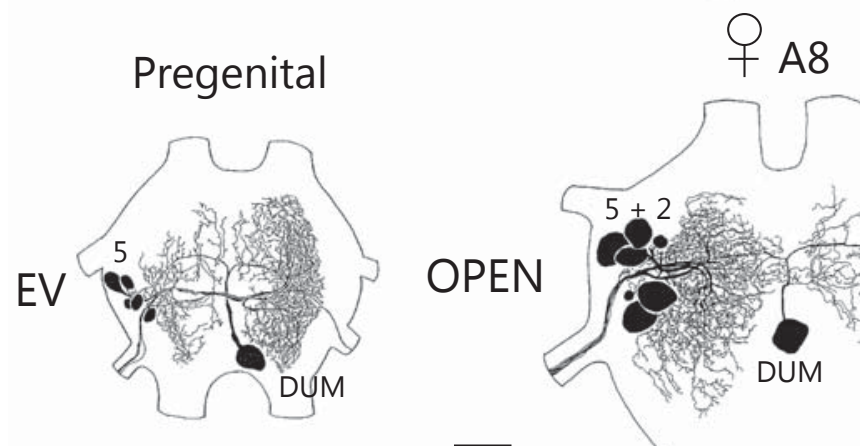

C
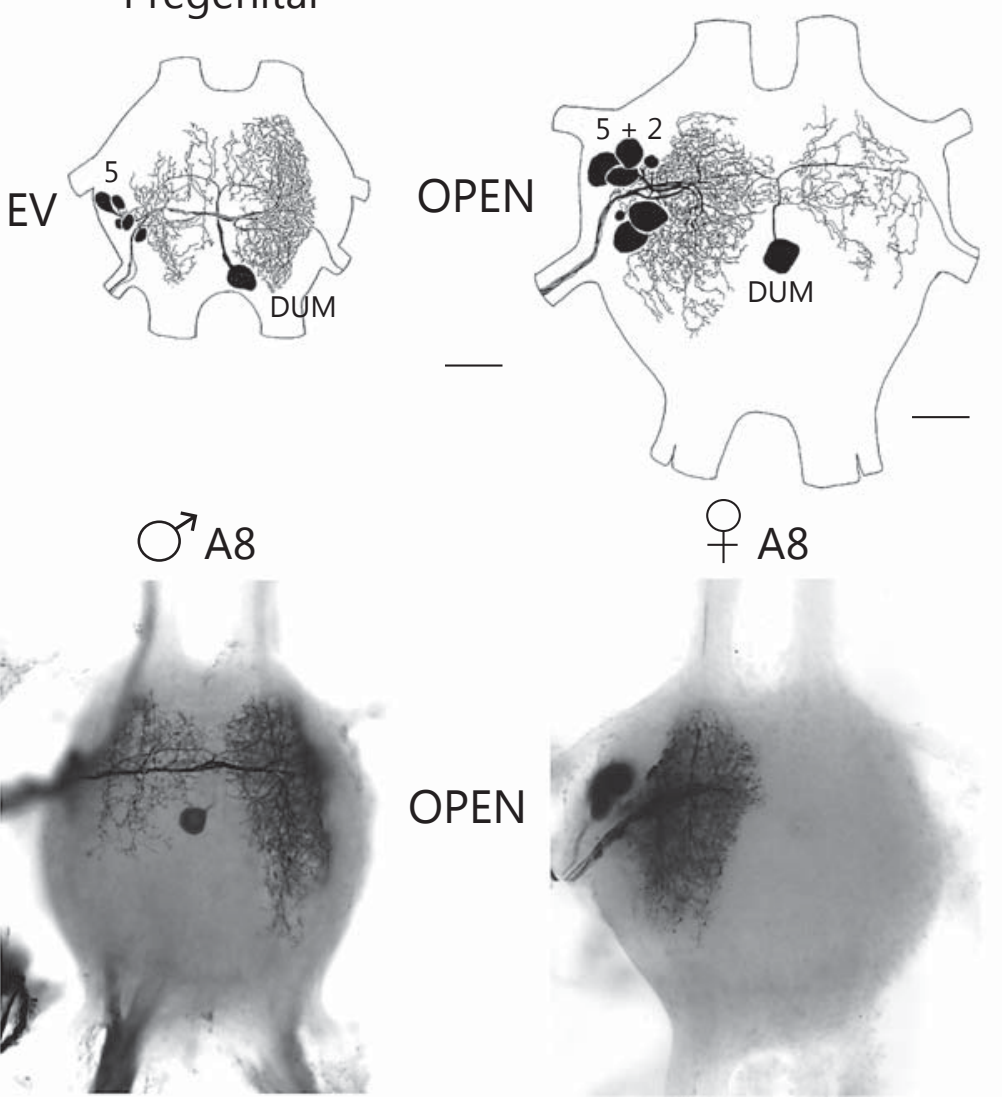

EV
2, but none of them had the large contralateral dendrites that distinguish the pregenital EV motor neurons (fig. 6B, $\mathrm{C}$, right). In fact, their neurites and fine branches were exclusively ipsilateral (fig. 6B; the contralateral branches belong to the DUM neuron, and see fig. $6 \mathrm{C}$, right, where the DUM neuron was palely stained). In addition, 2 extremely small motor neurons with cell bodies near the other
OPEN motor neurons were labeled in backfills from the OPEN muscle. These neurons had axons in a branch of Nv 2 that forked off caudal to the main supply of the OPEN muscle [Thompson et al., 1999]. The EV motor neurons of pregenital segments clearly had distinct and very large contralateral dendrites that were not found in the female A8. In the segment A8 of males, however, where the EV 
Table 3. Efferent neurons labeled in backfill preparations of terminal branches of lateral nerves to ovipositor and pregenital muscles

\begin{tabular}{|c|c|c|c|c|c|c|c|c|c|c|c|c|}
\hline \multirow[t]{2}{*}{ Muscles } & \multicolumn{8}{|c|}{ Preparations with the indicated numbers of $\mathrm{MNs}, \mathrm{n}$} & \multicolumn{3}{|c|}{ Neurons (median), $\mathrm{n}$} & \multirow[t]{2}{*}{ Animals, $\mathrm{n}$} \\
\hline & 1 & 2 & 3 & 4 & 5 & 6 & 7 & 8 & MNs & DUM & $\mathrm{CI}$ & \\
\hline PRO & & & 8 & & & & & & 3 & 1 & 1 & 8 \\
\hline PARA & & 1 & 11 & & & & & & 3 & 1 & 1 & 12 \\
\hline CLOSE & & & & & & 1 & 8 & & 7 & 1 & 1 & 9 \\
\hline MIV & & & 2 & 6 & & & & & 4 & 1 & 1 & 8 \\
\hline LIV & & 1 & 5 & & & & & & 3 & 1 & 1 & 6 \\
\hline RET & & 9 & & & & & & & 2 & 0 & 0 & 9 \\
\hline $3 \mathrm{EL}$ & & 4 & 1 & & & & 2 & & 2 & 0 & 0 & 7 \\
\hline OPEN & & & & & 3 & 1 & 8 & 1 & 7 & 1 & 0 & 13 \\
\hline EV & & 3 & & & 10 & & 2 & & 5 & 1 & 0 & 15 \\
\hline
\end{tabular}

Pregenital Nv 1 and Nv 2 branches corresponding to the branches to the indicated ovipositor muscles were filled. The data are displayed by number of preparations containing the indicated number of labeled motor neurons $(1-8)$. The median numbers of motor neurons (MNs) and DUM and CI neurons are also indicated. The range of values for DUM and CI neurons was $0-1$. Male and female pregenital data are combined. A total of 88 animals were used for this analysis.

muscle is also present, backfills of that muscle (fig. 6C, left) revealed motor neurons with a pregenital anatomy (compare with fig. $6 \mathrm{~B}$, left). The micrographs in figure $6 \mathrm{C}$ reveal the striking sexual dimorphism in the A8 segment, supporting the pregenital designation of males. As in more rostral pregenital segments, a single DUM neuron but no CI type neuron was found in the segment A8 of males.

Thus, the following correspondences of lateral nerve supply and efferent neurons are indicated (see also table 1): pregenital PARA and ovipositor PRO (Nv 1), pregenital MIV/LIV and ovipositor CLOSE (Nv 1), pregenital EV and ovipositor OPEN (Nv 2), and pregenital 3EL and ovipositor RET (Nv 2). The numbers of motor neurons and the clustering and positions of their cell bodies closely corresponded, except for 2 additional OPEN motor neurons, as did neurite branching patterns, except for the prominent contralateral EV motor neuron dendrites. In addition, the presence or absence of supply by DUM neurons and $\mathrm{CI}$ neurons matched between pregenital and female ovipositor backfills (also, see table 3 ).

\section{Comparison of Pregenital and Ovipositor Skeletons, \\ Muscles, and Innervation}

In genital segments, peripheral modifications associated with oviposition are extensive, contrasting with the plain, unadorned pregenital segments. The simpler exoskeleton of pregenital segments consists of dorsally located tergal plates of cuticle that overlap ventral sternal plates, and the plates of each segment overlap the plates of the subsequent one. Soft cuticle extends between the segmental plates of exoskeleton, allowing for relative movements: dorsoventral compression and expansion, telescoping movements, bending, and twisting. Internally, the sterna on their anterior lateral margins project stiff flattened extensions, the anterior and lateral apodemes (fig. 7). In pregenital abdominal segments, the internal surfaces of the sternal and tergal plates and apodemes provide skeletal surfaces for muscle attachments. In the genital segments of females, the tergal plates are relatively ordinary (not shown) but the sternal plates of segments A8 and A9, and the apodemes of A9 (ovipositor apodemes), by contrast, are greatly modified (fig. 7). Paired sternal appendages are also present in the form of ovipositor valves on segments A8 and A9. The caudal most visible sternal plate of the 11-segmented female abdomen is A8, and it is elongated with a curved tip that forms the egg guide (fig. 7, middle). The sternal plate of A9, on the other hand, is reduced to a tiny speck of cuticle (anterior intervalula, aiv) with a minute midline apodeme that is hidden between the bases of the paired ovipositor valves (fig. 7, right). The apodemes of A9, which are separated by soft cuticle from the sternal plate, are strikingly different from those of pregenital segments. They are enormously enlarged, sculpted, and sclerotized to become the prominent ovipositor apodemes in which the largest ovipositor muscles (OPEN) have their origins. Ventral and dorsal ovipositor valves are hinged at 
Fig. 7. Ventral exoskeleton of a typical pregenital segment and of the female ovipositor segments A8 and A9. The sternal plate of typical pregenital segments, including the male segment A8, bears anterior and lateral apodemes but not appendages (left). The sternal plate of segment A8 in females is elongated and holds the pair of ventral ovipositor valves but does not have lateral apodemes (middle). The greatly modified female A9 segment is characterized by large hinged anterior apodemes, now called the ovipositor apodemes, by an extreme reduction of the sternal plate to a small piece of midline cuticle situated between the bases of the valves, and by the other set of valves, the dorsal ovipositor valves (right).

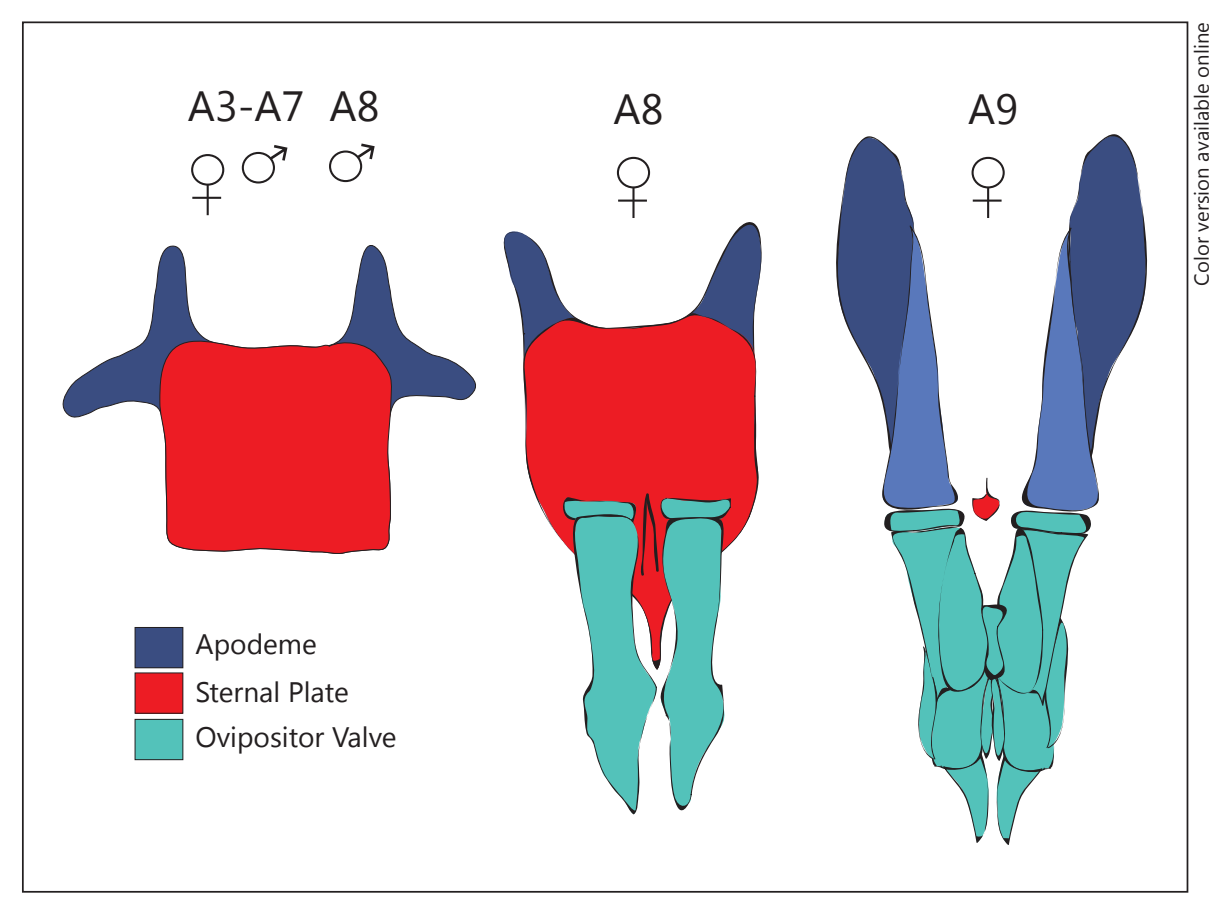

their bases and to the ovipositor apodemes, with the aiv lying between them. In segment A8, ovipositor muscle attachments include the inner surfaces of the ventral ovipositor valves, the ventral face of the ovipositor apodemes, the tergal and sternal plates of A8, and the tiny sternal plate of A9.

By aligning the muscle attachments on the modified cuticle in segment A8 with the simpler cuticle of pregenital segments, we uncovered a pattern of structural homology between ovipositor and pregenital musculatures (fig. 8). The intersegmental MIV and LIV muscles of pregenital segments, missing in the segment A8 of females, extend as sheets from the anterior region of the sternum to the anterior margin of the next posterior sternal plate or its apodeme (fig. 8A, B). These muscles together retract the posterior segment. Similarly, the candidate homologues, ovipositor CLOSE muscles in A8 extend from the anterior region of the sternal plate to insert posteriorly on the sternal plate of A9 which has been reduced to a tiny midline remnant (fig. 8C). Thus, each CLOSE muscle has 2 heads, medial and lateral, with broad origins on the sternal plate of A8, and the muscle is pinnate in shape, narrowing to insert on the small sternal plate and midline apodeme of A9. The ovipositor CLOSE muscles pull this plate back into the abdomen and, through a complex interaction with A9 muscles and cuticle [Thompson, 1986a], press the dorsal and ventral valves together.
Other missing muscles, the intersegmental EV muscles, are short muscles extending from the posterior margin of the local sternal plate anteriorly to the ventral face of the overlapping anterior apodeme of the next posterior segment (fig. 8A, B). Contraction of the EVs pushes the posterior segment backwards, protracting the ventral abdomen. In A8, the ovipositor OPEN muscle, its suggested homologue, likewise extends anteriorly from the local sternum, specifically its appendages (ventral valves), to the underside of the large ovipositor apodeme of A9 (fig. 8C). Shortening of this muscle, rather than protracting segment A9, causes the valves to rotate on their hinges, depressing them. The ovipositor CLOSE and OPEN muscles act as antagonistic muscles in the A8 of females, as do the pregenital MIV/LIV and the EV muscles, which retract and protract.

The PARA muscles in pregenital segments extend intersegmentally from the lateral medial region of the tergal plate to the anterior margin of the next posterior tergal plate (fig. 8A, B). In pregenital segments, their contractions shorten the dorsal abdomen. The ovipositor PRO muscle of A8 has its origin in the lateral medial region of the tergal plate of A8, similar to PARA muscles, but it inserts on the anterior tip of the ovipositor apodeme of A9 (fig. 8C). The insertion on the next posterior segment is like the PARA muscle, but the ovipositor apodeme is sternal, not tergal, so while the origins correspond and both muscles are in- 


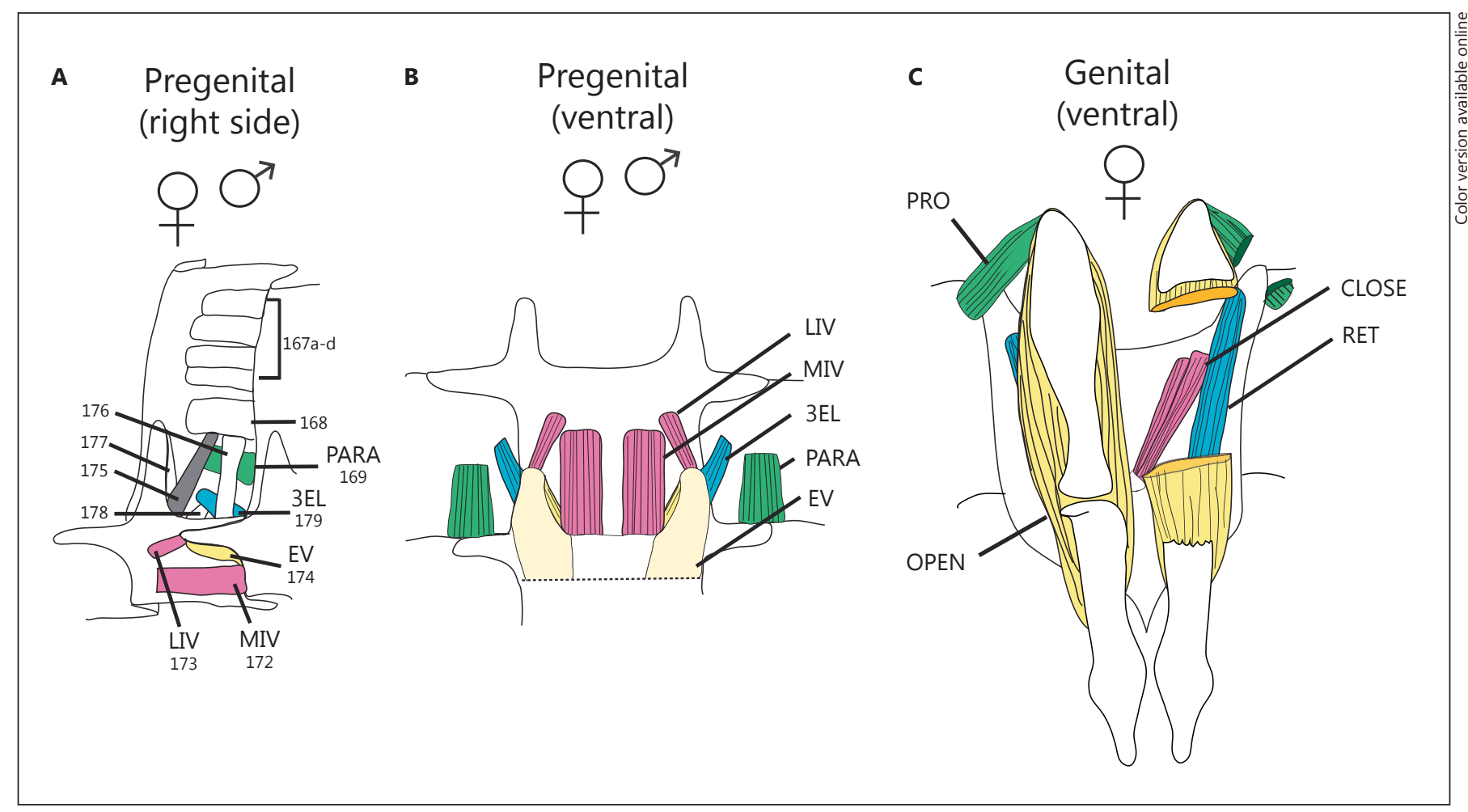

Fig. 8. Morphology of standard pregenital body wall musculature and ovipositor muscles of segment A8. Proposed homologies are indicated by the same color. A Internal lateral view of the right-side musculature of segment A3, the prototypical pregenital abdominal segment. Pregenital body wall muscles not found in the segment A8 of females are colored (colors refer to the online version only). The muscle 175 is a respiratory muscle not found in either male or female A8 segments (gray). Anterior is to the left. B Internal dorsal view of the pregenital body wall muscles not found in the female segment A8. C Internal dorsal view of ovipositor muscles of the female A8 segment, with the ovipositor apodeme, large OPEN muscle, and a portion of the ovipositor valve cut away on the right side to reveal the underlying CLOSE and RET muscles. Muscle numbers after Snodgrass [1935]; see table 1. tersegmental, the insertions are different between PARA and PRO muscles. Finally, the 3EL muscles are oblique tergo-sternal muscles that cause sliding of the tergum across the sternum within one segment. These muscles extend from the posterior lateral margin of the sternal plate forward to the lateral medial region of the tergum within a segment (fig. 8A, B). The ovipositor RET muscles extend from pouches near the bases of the ventral ovipositor valves anteriorly to the anterior lateral part of the sternal plate of A8 (fig. 8C). The anterior attachment on the sternal plate corresponds to the 3EL anatomy, but the other attachment also in the sternum (to the valves) is distinct from the $3 \mathrm{EL}$ tergal attachment. These last 2 ovipositor muscles appear to have origins corresponding to the candidate pregenital muscle homologues but seem to have different insertions onto the modified female exoskeleton.

The structural homologies suggested by our comparative analysis of pregenital and ovipositor muscles and cu- ticle directly connect to the findings of a serially homologous efferent neural supply of each of the pregenital and ovipositor muscles studied (fig. 9). The full populations of efferent neurons supplying pregenital muscles missing in the segment A8 of females and the efferent neuron supply of ovipositor muscles in segment A8 constitute evidence of structural homology, including similar axonal trajectories in lateral nerve branches, positions of cell bodies and neurites in local and anterior adjacent ganglia, and the numbers and types of neurons found (motor neurons, DUM neurons, or CI neurons).

\section{Discussion}

To summarize our findings, while female grasshoppers are substantially modified for oviposition behavior, multiple levels of structural correspondence were none- 


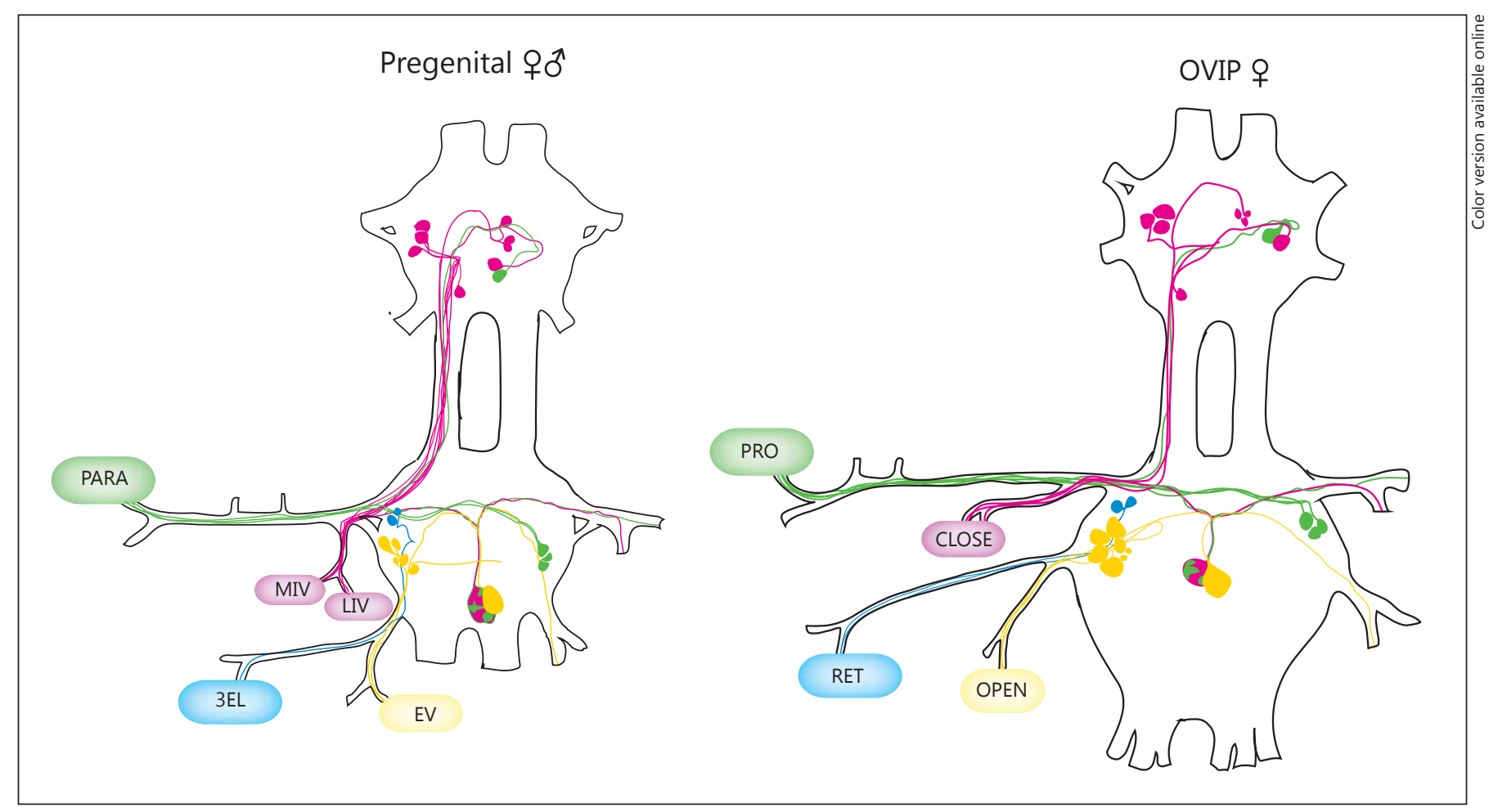

Fig. 9. Summary of the structurally homologous efferent neurons that supply pregenital body wall muscles and the ovipositor muscles of segment A8. Pregenital motor neurons, DUM neurons, and CI neurons (left); ovipositor neurons (right). The diagram indicates homologues and colors correspond to the muscle homologies shown in figure 8 (colors refer to the online version only). Pregenital and female A8 pairings: PARA and PRO, MIV/LIV and CLOSE, 3EL and RET, and EV and OPEN. This summary diagram is based on data shown in figures 5 and 6, table 3, Thompson and Roosevelt [1998], and Thompson et al. [1999]. theless recognizable between pregenital and genital segments. Efferent neurons as well as ovipositor nerves, muscle, and skeleton align in a straightforward way with the morphology of the pregenital abdomen of males and females. Nerve branching patterns in pregenital and genital segments directly corresponded. This result was not unexpected given its general occurrence. Investigators have shown that a similar pattern of lateral nerves and branches in pregenital and genital segments A1 to A9 is pioneered in the same manner in grasshoppers, which are considered to have primitive characteristics, as in Drosophila with its more derived characteristics [Meier et al., 1991]. Identification of early embryonic afferent and efferent pioneers and their organization also highlights the conserved developmental mechanisms underlying the construction of the peripheral nervous system across segments within one species [Meier and Reichert, 1990; Meier et al., 1991; Sink and Whittington, 1991; Meier and Reichert, 2004]. The development of peripheral nerves includes a key period in which afferent and efferent pio- neers interact in embryonic limb rudiment ectoderm. The transient appearance of embryonic limb buds starting at $30 \%$ of embryogenesis and beginning to be reduced in pregenital segments by $55 \%$ [Bentley et al., 1979] is essential for peripheral nerve development because guidepost cells and limb-related afferent neurons lead to nerve pathway formation [Meier et al., 1991]. In ovipositor segments, where the limb buds are retained as ovipositor valve precursors, similarities in nerve branching patterns persist even in the face of a derived adult morphology. Our backfill studies have determined that overall similar sets of efferent neurons with respect to neuron numbers, types, cell body positions, primary neurite trajectories, the distribution of fine branches, and axon pathways in lateral nerve branches are found in pregenital ganglia of males and females. Further, when modifications of the ovipositor exoskeleton are understood in relation to the simpler pregenital exoskeleton, the origins and insertions of the ovipositor muscles, with some reattachments, fusion, and hypertrophy, can be clearly aligned to the at- 
tachments of muscles in pregenital abdominal segments. Therefore, each of the ovipositor muscles of A8 is likely to represent a female specific 'missing' pregenital muscle (or the fusion of 2 of them). Thus, our evidence for suggesting a serial homology of ovipositor and pregenital elements rests on the work of others describing embryonic neural, muscular, and skeletal patterns but also on a detailed comparative analysis of the innervation of the 'missing muscles' and the precise alignment we found between the pregenital neuronal morphology and the female's ovipositor motor system. Significantly, there is little structural difference overall when whole-nerve backfills are compared between pregenital and genital segments. Then, when the subset of specific neurons that supply the pregenital muscles that appeared absent from the female segment A8 were compared to the ovipositor neurons, a clear pattern of structural homology emerged.

Useful studies of embryonic muscle development in the abdomen have also been undertaken in a species closely related to $S$. americana, i.e. L. migratoria, in which 4 of the pregenital muscles highlighted in this study were directly examined [Xie et al., 1992; Steffens et al., 1995]. The MIV, LIV, and EV muscle pioneers were found to be present only in the abdominal segments and not in the thoracic ones. An initial pattern of early muscle pioneers is established by $35 \%$ of embryonic development. The MIV, LIV, and EV muscles develop uniquely in abdominal segments from muscle pioneers that appear later during a second wave of muscle development which takes place at the 50\% embryonic stage [Steffens et al., 1995]. The second-wave pioneers replace the early precursor cells of the ventral abdomen which atrophy and are eventually lost. In thoracic segments where these late pioneers do not occur, the early precursors are retained to become identified adult muscles. The adult pattern of thoracic and abdominal body wall muscles is evident by the $70 \%$ embryonic stage. The MIV, LIV, and EV muscle pioneers are reiterated along the abdomen, at least to segment A7, but have not been studied in genital segments. The PARA muscle, whose precursor appears during the first wave of muscle development, shifts its position from being part of the dorsal group of muscle precursors (dorsal longitudinal muscles) to the lateral body wall group [Xie et al., 1992]. These examples demonstrate the serial homology of pregenital muscles, in fact for 4 of the 5 muscles studied here, as well as the fidelity of their innervation in the face of changes. It is clear from studies of development of the PARA muscle that the reorganization of muscle attachments is possible, and in ovipositor OPEN muscles, as with flight muscles, hypertrophy during adult develop- ment can also occur [Rose et al., 2001]. In their study of muscle development, Xie et al. [1992] concluded that diversification of segmental muscle patterns could be produced by loss, fractionation, fusion, and shift of the position of muscle precursor cells. It is clear that the apparent muscle reorganization associated with the ovipositor could occur through known developmental mechanisms, such as fusion and shift of position. We consider the innervation patterns we have observed to provide additional evidence suggestive of a serial homology of both nerve and muscle.

Interesting differences in neuronal morphology were also found that appear to show how modification and diversification can take place within the context of homology. Among pregenital ovipositor homologues, some motor neurons $(\mathrm{EV})$ were found to have neurites very different from their putative ovipositor homologues. Such variance in the presence of major dendrites has also been observed between crayfish and squat lobsters in comparative studies [Wallis et al., 1995]. Evidence for serial homology is ideally based on evolution and development from segmentally repeated precursors and not on uniformity of adult structure or function [Kutsch and Heckmann, 1995]. Oviposition presents an example of how differentiation events from reiterated nerve, muscle, and skeleton can result in a highly specialized and novel adult behavior. Despite the variations in adult morphology, the accumulated evidence suggests that oviposition specializations in segment A8 rest upon structures that are clearly evident and identifiable in pregenital abdominal segments of males and females and are most likely derived from common precursors.

A frequent observation in studies addressing the neurobiology of behavioral evolution is that the nervous system appears much less modified than do peripheral structures, including appendages [Edwards and Palka, 1991; Katz and Harris-Warrick, 1999; Rast and Braunig, 2001]. Many productive investigations into the evolution of neural circuits for novel behavior have focused on comparisons across species with known evolutionary relationships [Katz, 2010]. In some of these studies, CPG neurons have been identified. For example, CPGs are compared in the context of variants of a behavior, such as in different forms of swimming, e.g. lateral and dorsoventral, in nudibranch mollusks [Newcomb and Katz, 2009]. Animals which do not display the behavior of their relatives, e.g. mollusks that do not swim or flightless insects, are studied to see whether 'swim' or 'flight' neurons are present, suggesting whether the behavioral circuits have been lost or whether the absence of behavior is the prim- 
itive condition of a common ancestor [Arbas, 1983; Arbas et al., 1991; Rast and Braunig, 2001; Whiting et al., 2003; Katz and Newcomb, 2006]. Comparative neuroethological studies, at the level of identified neurons, have shown that similar neural circuits may underlie diverse behaviors, homologous neurons may play different behavioral roles in different animals, and that behavior can be lost in evolution [Arbas, 1983; Paul, 2004; Berkowitz, 2008; Katz, 2010]. Lost behavior can also be recovered, as seen in examples of stick insects where wings have been lost and regained [Whiting et al., 2003]. In segmented animals such as arthropods and vertebrates, differently specialized segments within one animal can also be compared [Wallis et al., 1995; Technau et al., 2005; Grillner, 2006; Niven et al., 2008; Stephenson-Jones et al., 2012]. This strategy is being employed to compare neural circuits across phylogeny for behavior such as locomotion and respiration [Grillner, 2003; Ryczko et al., 2010; Cangliano et al., 2012].

Our analysis has revealed multiple homologous structural elements associated with oviposition behavior (peripheral and central): serial appendages, muscles, lateral nerve branches, and a common morphology of the efferent neuronal supply. Within the context of homology, central modifications of some motor neuron structures, peripheral variations of skeletal muscles, and the appearance of ovipositor valves and apodemes in female segments have taken place. These results are consistent with the idea that preexisting segmental structures, both central and peripheral, form the basis of oviposition digging behavior. From the hemimetabolous grasshoppers to the completely metamorphic holometabolous insects and even to the silverfish with its primitive insect features, embryonic patterns of segmental neuroblasts have been found to be essentially identical [Goodman and Bate, 1981; Thomas et al., 1984; Truman and Ball, 1998]. In retrospect, it should have come as no surprise that the female grasshopper's genital segment bears such a remarkable similarity to pregenital segments of males and females.

\section{Acknowledgements}

This study was funded by NSF No. IBN 9904882, and by grants from the Gary Fund, the Gravatt Foundation, and Agnes Scott College.

The authors are grateful to Karen Mesce for helpful comments on this report, and to Cynthia Harley for tireless and expert figure production. Mark Sanders and Eric Schabtach are thanked for assistance with photomicrographs.

\section{References}

Albrecht FO (1953): The Anatomy of the Migra- Burrows M, Bevan S (1999): Maps of the somata tory Locust. London, Athlone Press.

Arbas EA (1983): Neural correlates of flight loss in a Mexican grasshopper, Barytettix psolus. 1. Motor and sensory cells. J Comp Neurol 216: 369-380.

-Arbas EA, Meinertzhagen IA, Shaw SR (1991): Evolution in nervous systems. Annu Rev Neurosci 14:9-38.

-Ayali A, Lange AB (2010): Rhythmic behaviour and pattern-generating circuits in the locust: key concepts and recent updates. J Insect Physiol 56:834-843.

- Bentley D, Keshishian H, Shankland M, ToroianRaymond A (1979): Quantitative staging of embryonic development of the grasshopper, Schistocerca nitens. J Embryol Exp Morphol 54:47-74.

Berkowitz A (2008): Physiology and morphology of shared and specialized spinal interneurons for locomotion and scratching. J Neurophysiol 99:2887-2901.

Breidbach O, Kutsch W (1990): Structural homology of identified motoneurones in larval and adult stages of hemi- and holometabolous insects. J Comp Neurol 297:392-409. of efferent neurons with axons in the lateral nerves of locust abdominal ganglia. J Exp Biol 202:2911-2923.

Cangliano L, Hill RH, Grillner S (2012): The hemi-segmental locomotor network revisited. Neurosci 210:33-37.

Da Silva R, Lange AB (2011): Evidence of a central pattern generator regulating spermathecal muscle activity in Locusta migratoria and its coordination with oviposition. J Exp Biol 214: 757-763.

Edwards JS, Palka J (1991): Insect neural evolution - a fugue or an opera? Sem Neurosci 3: 391-398.

Ferber M, Pfluger H-J (1990): Bilaterally projecting neurons in pregenital abdominal ganglia of the locust: anatomy and peripheral targets. J Comp Neurol 302:447-460.

Ficcapointe G, Lange AB (1996): Control of the motor pattern generator in the VIIth abdominal ganglion of Locusta: descending neural inhibition and coordination with the oviposition hole digging central pattern generator. J Insect Physiol 42:791-798.
Fuchs E, Hulata E, Ben-Jacob E, Ayali A (2006): Adult, sex-specific behavior characterized by elevated neuronal functional complexity. Neuroreport 17:1153-1158.

Goodman CS, Bate M (1981): Neuronal development in the grasshopper. Trends Neurosci 4: 103-169.

Grillner S (2003): The motor infrastructure; from ion channels to neuronal networks. Nat Rev Neurosci 4:573-586.

-Grillner S (2006): Biological pattern generation: the cellular and computational logic of networks in motion. Neuron 52:751-766.

-Jarvis E, Bruce HS, Patel NH (2012): Evolving specialization of the arthropod nervous system. Proc Natl Acad Sci USA 109:10634-10639.

-Jorgensen WK, Rice MJ (1983): Superextension and supercontraction in locust ovipositor muscles. J Insect Physiol 29:427-448.

Kalogianni E (1996): Morphology and physiology of abdominal projection interneurons in the locust with mechanosensory inputs for ovipositor hair receptors. J Comp Neurol 366: 656-673.

Katz PS (2010): Comparative studies provide evidence for neural reuse. Behav Brain Res 33: 278-279. 
Katz PS, Harris-Warrick RM (1999): The evolution of neuronal circuits underlying speciesspecific behavior. Curr Opin Neurobiol 9: 628-633.

Katz PS, Newcomb JM (2006): A tale of two CPGs: phylogenetically polymorphic networks; in Kaas JH (ed): Evolution of Nervous Systems: a Comprehensive Reference. Oxford, Elsevier, pp 367-374.

Kutsch W, Heckmann R (1995): Motor supply of the dorsal longitudinal muscles. 1. Homonomy and ontogeny of the motoneurones in locusts (Insecta, Caelifera). Zoomorphology 115:179-195.

Lange AB, Orchard I, Loughton BG (1984): Neural inhibition of egg-laying in the locust Locusta migratoria. J Insect Physiol 30:271-278.

Lewis GW, Miller PL, Mills PS (1973): Neuromuscular mechanisms of abdominal pumping in the locust. J Exp Biol 59:149-168.

Matsuda R (1976): Morphology and Evolution of the Insect Abdomen. New York, Pergamon Press.

McKenna KE, Chung SK, McVary KT (1991): A model for the study of sexual function in anesthetized male and female rats. Am J Physiol 261:1276-1285.

Meier T, Chabaud F, Reichert H (1991): Homologous patterns in the embryonic development of the peripheral nervous system in the grasshopper Schistocerca gregaria and the fly Drosophila melanogaster. Development 112:241253.

Meier T, Reichert H (1990): Embryonic development and evolutionary origin of the orthopteran auditory organs. J Neurobiol 21:25922610.

Meier T, Reichert H (2004): Serially homologous development of the peripheral nervous system in the mouthparts of the grasshopper. J Comp Neurol 305:201-214.

Newcomb JM, Katz PS (2009): Different functions for homologous serotonergic interneurons and serotonin in species-specific rhythmic behaviours. Proc Biol Sci 276:99-108.

-Newland PL, Yates P (2008): Contact chemoreception in egg-laying behavior of locusts. J Insect Physiol 54:273-285.

Niven JE, Graham CM, Burrows M (2008): Diversity and evolution of the insect ventral nerve cord. Ann Rev Entomol 53:253-271.
Paul DH (2004): Projection and local interneurons in the sixth abdominal ganglion of the sand crab Emerita analoga (Hippidae). J Comp Neurol 480:253-271.

Qadri MAH (1940): On the development of the genitalia and their ducts in Orthopteroid insects. Trans R Ent Soc Lond 90:121-175.

Rast GF, Braunig P (2001): Insect mouthpart motor patterns: central circuits modified for highly derived appendages? Neurosci 108: 167-176.

- Rose U (2004): Morphological and functional maturation of a skeletal muscle regulated by juvenile hormone. J Exp Biol 207:483-495.

Rose U, Ferber M, Hustert R (2001): Maturation of muscle properties and its hormonal control in an adult insect. J Exp Biol 206:445-455.

Ryczko D, Dubuc R, Cabelquen JM (2010): Rhythmogenesis in axial locomotor circuits: an interspecies comparison. Prog Brain Res 187:189-211.

Schmah M, Wolf H (2003): Inhibitory motor neurons supply body wall muscles in the locust abdomen. J Exp Biol 206:445-455.

Schmitt JB (1954): The nervous system of the pregenital abdominal segments of some orthoptera. Ann Entomol Soc Am 47:677-682.

Seabrooke WD (1968): The innervation of the terminal abdominal segments (VIII-XI) of the desert locust, Schistocerca gregaria. Can Ent 100:693-715.

Sink H, Whittington PM (1991): Pathfinding in the central nervous system and periphery by identified embryonic Drosophila motor axons. Development 112:307-316.

Snodgrass RE (1935): The abdominal mechanisms of a grasshopper. Smithson Misc Collect 94:1-89.

- Steffens G, Kutsch W, Xie F, Reichert H (1995): Segmental differentiation processes in embryonic muscle development of the grasshopper. Dev Genes Evol 204:453-464.

Stephenson-Jones M, Ericsson J, Robertson B, Grillner S (2012): Evolution of the basal ganglia: dual-output pathways conserved throughout vertebrate phylogeny. J Comp Neurol 520:2975-2973.

-Technau GM, Berger C, Urbach R (2005): Generation of cell diversity and segmental pattern in the embryonic central nervous system of Drosophila. Dev Dyn 235:861-869.
Thomas JB, Bastiani MJ, Bate M, Goodman CS (1984): From grasshopper to Drosophila: a common plan for neuronal development. $\mathrm{Na}-$ ture 310:203-207.

Thompson KJ (1986a): Oviposition digging in the grasshopper. 1. Functional anatomy and the motor programme. J Exp Biol 122:387-411.

Thompson KJ (1986b): Oviposition digging in the grasshopper. 2. Descending neural control. J Exp Biol 122:413-425.

Thompson KJ, Roosevelt JL (1998): Comparison of neural elements in sexually dimorphic segments of the grasshopper, Schistocerca americana. J Comp Neurol 394:14-28.

Thompson KJ, Siegler MVS (1991): Anatomy and physiology of spiking local and intersegmental interneurons in the median neuroblast lineage of the grasshopper. J Comp Neurol 305: 659-675.

- Thompson KJ, Sivanesan SP, Campbell HR, Sanders KA (1999): Efferent neurons and specialization of abdominal segments in grasshoppers. J Comp Neurol 415:65-79.

Tousson E, Hustert R (2000): Central projections from contact chemoreceptors of the locust ovipositor and adjacent cuticle. Cell Tissue Res 302:285-294.

Truman JW, Ball EE (1998): Patterns of embryonic neurogenesis in a primitive wingless insect, the silverfish, Ctenolepisma longicauda$\mathrm{ta}$ : comparison with those seen in flying insects. Dev Genes Evol 208:357-368.

Vincent JFV (1976): How does the female locust dig her oviposition hole? J Entomol 50:175181.

-Wallis EJ, Paul DH, Antonsen BL, Hollenberg R (1995): Variations on a segmental theme: muscle receptor organs and extensor neuromusculature in the squat lobster Munida quadrispina (Anomura, Galatheidae). J Exp Biol 198:2453-2463.

Wanischeck M, Rose U (2005): Unusual tension reception in an insect. J Neurobiol 65:115124.

Whiting MF, Bradler S, Maxwell T (2003): Loss and recovery of wings in stick insects. Nature 421:264-267.

Xie F, Meier T, Reichert H (1992): Embryonic development of muscle patterns in the body wall of the grasshopper. Roux's Arch Dev Biol 201: 301-311. 